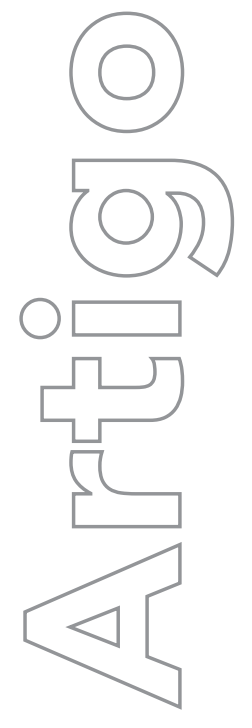

revista

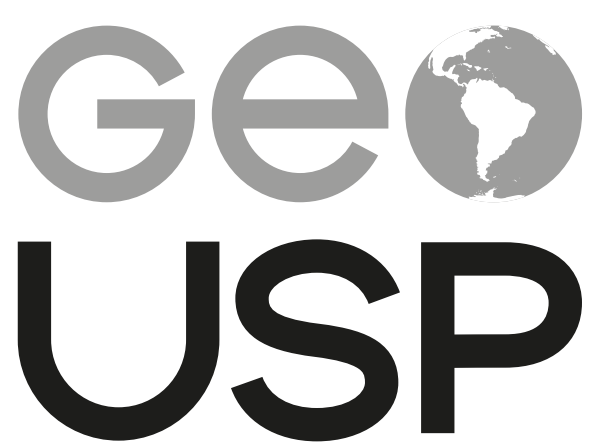

espaço e tempo

Volume $24 \cdot n^{\circ} 2(2020)$

ISSN 2179-0892
Entre "o Centro e

o Cosmo": ensaio interpretativo sobre a dimensão espacial do sagrado por meio da música candomblecista

\section{Yasmin Estrela Sampaio}

Universidade do Estado do Pará, Belém, PA, Brasil e-mail: yasminsampaio98@gmail.com

(1D) 0000-0003-1038-3247

Edgar Monteiro Chagas Junior Universidade da Amazônia, Belém, PA, Brasil e-mail: edgarchagas@yahoo.com.br

(1) 0000-0003-2048-560X

p. $226-242$

Como citar este artigo:

SAMPAIO, Y. E.; CHAGAS JUNIOR, E. M. Entre "O Centro e o Cosmo": ensaio interpretativo sobre a dimensão espacial do sagrado por meio da música candomblecista. Geousp-Espaço e Tempo (On-line), v. 24, n. 2, p. 226-242, ago. 2020. ISSN 2179-0892.

Disponivel em: http://www.revistas.usp.br/geousp/article/ view/165988. doi: https://doi.org/10.11606/issn.2179-0892. geousp.2020.165988.

\section{(c) (1)}

Este artigo está licenciado sob a Creative Commons Attribution 4.0 Licence 


\title{
Entre "o Centro e o Cosmo": ensaio interpretativo sobre a dimensão espacial do sagrado por meio da música candomblecista
}

\section{Resumo}

A música é um dos elementos essenciais nos cultos de Candomblé. Ao lado da dança, concorre para a identificação de cada orixá e seus ritos. É uma forma de expressão que divulga e mantém viva a história de algumas tradições orais africanas, contribuindo para a formação identitária e para a percepção do caráter sagrado dos lugares de celebração. A memória é o elo entre dois lugares em tempos diferentes: Orum e Ayê,' que espacializam a cosmogonia do Candomblé. Concebendo a religião como um sistema cultural - que se caracteriza por diferentes modalidades de cultos e celebrações -, ela tem na música um dos elementos que vinculam o humano e o sagrado e mobiliza maneiras de ser e existir no espaço imediato celebrativo. Com isso, à luz da teoria do espaço sagrado, de Zeny Rosendahl, e à de música e sagrado, de Lily Kong, este ensaio procura compreender a maneira pela qual a música é um elemento essencial que integra a produção do espaço simbólico dos terreiros de Candomblé.

Palavras-chave: Música. Espaço sagrado. Cosmogonia. Candomblé.

\section{"Center and Cosmos": interpretation about the spatial dimension of the candomblecist sacred music}

\begin{abstract}
Music is one of the most important element in Candomble cults. Combined with the dance, it collaborates with the orixás identification and their rites. It's a form of expression that disseminates and keeps alive the history of some African oral traditions collaborating in the formation of identity and the perception of the sacredness
\end{abstract}


of celebration places. Memory is the connection between two places at different times: the Orum and Ayê, that spatialize the Candomblés cosmogony. Considering the religion as a cultural system - which is characterized by different modalities of worship and celebrations - this one, has on the music a one of the elements that creats relationships between humans and what we can call sacred, that mobilizes ways of being and existing in the immediate celebratory space. To help us and elucidate this essay, we'll work with Zeny Rosendahl's sacred space theory and Lily Kong's music theory, to discuss and understand the way in which music is an essential element that contributes to the production in Candomblés temple.

Keywords: Music. Sacred Space. Cosmogony. Candomblé.

\section{Entre "le Centre et le Cosmos": étude sur la dimension spatiale du sacré à travers la musique du candomblé}

\section{Résumé}

La musique est l'un des éléments essentiels du culte de candomblé. La danse sert à collaborer à l'identification de chaque orixá et de leurs rites. C'est une forme d'expression qui dissémine et permet de garder en vie l'histoire de certaines traditions orales africaines et collaborer à la formation de l'identité et à la perception du caractère sacré des lieux de célébration. La mémoire est le lien entre deux lieux à différents moments: l'Orum et l'Ayê qui sont les endroits de la cosmogonie du Candomblé. Comprendre la religion comme un système culturel qui se caractérise par différentes modalités de cultes et de célébrations - ce dernier a, en musique, l'un des éléments d'élaboration des liens entre l'humain et le sacré qui mobilise les manières d'être et d'exister lors des rites sacrés. Ainsi, à la lumière de la théorie des lieux sacrés de Zeny Rosendahl et de la théorie musicale de Lily Kong, nous discutons dans cet essai d'un exercice pour comprendre comment la musique est un élément essentiel qui contribue à la production des espaces symboliques du temple de Candomblé.

Mots-clés: Musique. Espace sacré. Cosmogonie. Candomblé. 


\section{Introdução}

A presente comunicação parte de um exercício sobre as possibilidades de interação entre os estudos da Geografia e os das Ciências da Religião, tendo por base a análise do fenômeno religioso em relação à produção do espaço sagrado a partir do fazer musical nos cultos afro-religiosos. Buscou-se compreender a religião como um sistema cultural estruturado com base nos significados, símbolos e concepções que elaboram o sentido do sagrado na produção de um espaço vivido pelos praticantes candomblecistas.

$\bigcirc$ Candomblé tem determinadas práticas de culto em que se utilizam representações musicais, a partir de cantigas pelas quais as letras reproduzem a memória da cosmogonia africana (Lühning, 1990) reforçando a existência do espaço sagrado.

Assim, pode-se dizer que há um elo de comunicação construído a partir do ritual entre o humano e os orixás, em que a música é o elemento mediador dessa relação concebida a partir da construção da cosmogonia dos cultos afro-religiosos que também influencia a organização espacial do terreiro. As letras dos cânticos acompanhadas dos atabaques, mobilizam os corpos e dinamizam o ritual conforme a especificidade de cada orixá, elaborando, assim, uma identificação corpo-música-rito com o lugar onde é praticado. Atribui-se à música a capacidade de transmissão de imagens guardadas na memória dos candomblecistas, sendo, portanto, segundo Marinho (2010), um depositário do elo de um lugar com outro lugar convertendo-se em uma revisitação de um tempo presente a outro.

O exercício de um estudo do espaço, a partir da possibilidade de interação da Geografia com a Ciência da Religião aqui proposto, faz parte de uma necessidade interpretativa que abranja o fenômeno cultural estudado enviesado pela tentativa de apreensão da maneira pela qual os espaços são modificados por uma intencionalidade de indivíduos de controlar o território religioso como forma de manutenção da experiência e da vivência na sua profissão de fé. Assim, "ambas, a geografia e a religião, se encontram através da dimensão espacial, uma porque analisa o espaço, a outra porque como fenômeno cultural, ocorre espacialmente" (Rosendahl, 1995, p. 45). Ademais, tratando-se de um estudo acerca de uma religião de matriz africana, é imprescindível construir um debate e analisar a manifestação do fenômeno religioso no espaço a partir do fazer musical, sendo este um elemento estruturante fundamental nos cultos de Candomblé e que acompanha todos os ritos de um terreiro, deste a iniciação de um indivíduo na religião até os ritos fúnebres.

Com isso, a intenção é compreender a prática musical nos terreiros de Candomblé como um elemento simbólico propulsor das ações sociais presente no espaço. De acordo com Rosendahl (2012), existe um impulso que leva o homem religioso a agir sobre seu ambiente e qualifica-o com formas espaciais diretamente ligadas às suas necessidades. "São marcas simbólicas que respondem aos desejos do devoto em suas práticas espaciais" (Rosendahl, 2012, p. 25). As práticas espaciais religiosas contribuem para a criação de um território que possibilita o fortalecimento das experiências religiosas coletivas e individuais garantindo e estabelecendo o domínio dos grupos religiosos no espaço.

Antes disso, no entanto, cabe uma breve explanação sobre as possibilidades de um estudo interdisciplinar delineado na imbricação entre Geografia e Ciências da Religião como condição de 
sustentação do que se pode considerar um "fundamento da concepção", ou seja, que estrutura e organiza o pensamento sobre aquilo que se quer fazer compreender.

\section{Geografia, música e religião: uma análise interdisciplinar}

Gil Filho (2012a) descreve a religião como um modo específico de condicionamento estrutural da realidade, a partir do pensamento de Cassirer (1977), em que as formas simbólicas constroem o mundo "real" e espiritual, entre as quais estão linguagem, ciência, religião, arte e mito, fortalecidas pelo processo de pensamento, tendo por objetivo lidar com qualquer indício de intimidação à ordem nas dimensões intelectual, física e moral. Nessa linha de pensamento, Geertz (2008, p. 67) afirma que:

Os símbolos sagrados funcionam para sintetizar o ethos ${ }^{2}$ de um povo, o tom, o caráter e a qualidade da sua vida, seu estilo e disposições morais e estéticos e sua visão de mundo o quadro que fazem do que são as coisas na sua simples atualidade, suas idéias mais abrangentes sobre ordem.

Rosendahl (1995) classifica como territorialidades a maneira pela qual ocorre a organização de uma religião no espaço que passa a ser reconhecida como instituição. Para isso, se estabelece o controle sobre pessoas e amplia-se continuamente o território com base em práticas coletivas de controle. $\bigcirc$ espaço sagrado é descrito pela autora como o lugar onde o divino se manifestou e expressa sua presença na terra. Eliade (1991) o caracteriza como espaço cosmicizado como o centro que reproduz a criação do mundo. Os padrões simbólicos representam no espaço os aspectos culturais da comunidade, de tal modo que o espaço pode ser observado conforme os valores simbólicos nele representados (Rosendahl, 1995).

Territorialidade religiosa, por sua vez, significa o conjunto de práticas desenvolvido por instituições ou grupos no sentido de controlar um dado território, onde o efeito do poder do sagrado reflete uma identidade de fé e um sentimento de propriedade mútuo. A territorialidade é fortalecida pelas experiências religiosas coletivas ou individuais que o grupo mantém no lugar sagrado e nos itinerários que constituem seu território. De fato, é pelo território que se encarna a relação simbólica que existe entre cultura e espaço (Rosendahl, 2005, p. 197).

espaço produzido a partir das práticas de Candomblé tem nos símbolos a representação dos orixás que são acionados nas liturgias, os quais são representados por objetos materiais organizados não aleatoriamente no terreiro. Nesse sentido, o espaço vivido se apresenta em interação com a disposição dos objetos rituais, o que nos permite pensar na sua orientação em torno da mitologia que orienta as formas e os conteúdos culturais dos praticantes do candomblé.

2 Geertz descreve ethos como o tom, o caráter, a qualidade de vida, o estilo e as disposições morais e estéticas de um povo. 
Sob o domínio mítico o espaço está orientado a fixação do sentimento mítico. Deste modo, como sugere Cassirer $\left(2011,{ }^{3}\right.$ p. 255-256) o pensamento mítico estabelece distinções espaciais determinadas de caráter expressivo e intuitivo e consequentemente rompe com sua homogeneidade. Portando o "aquil e o "lá", o "acima" e o "abaixo", o "sagrado e profano" se apresentam como intercambiáveis, mas com particularidades de significado (Gil Filho, 2012a, p. 86).

A organização social de alguns terreiros se estabeleceu a partir de um vínculo histórico baseado em alianças de parentesco religioso entre negros que haviam sido destituídos de seus grupos pela escravidão. São criadas familias com parentescos espirituais a fim de se estabelecer uma coalizão entre diferentes grupos étnicos (Silva, 2005).

A coesão social dos terreiros é concebida a partir de laços espirituais com o intuito de reproduzir o modelo de culto africano, originalmente familiar e exclusivo de uma linhagem, como afirma Silva (2005), na qual havia o culto de apenas uma ou poucas divindades, sendo cultuadas em diferentes regiões africanas. Ainda segundo o referido autor, no Brasil não foi possível reconstruir este modelo de culto, uma vez que as familias foram separadas e diversas etnias foram agrupadas, reunindo o culto de diversas entidades em um único espaço.

sistema de estruturação social das familias de santo baseado na espiritualidade atua como forma simbólica e age, segundo Gil Filho (2012b), como estruturante da realidade sobre campos de ação, ou seja, espacialidades do mundo. Portanto "as espacialidades são tanto o esquema perceptual de determinada forma simbólica quanto representação objetivada do fenômeno" (Gil Filho, 2012b, p. 57). Logo, as formas simbólicas são formas culturais que podem ser compreendidas a partir de diversas características, com funções simbólicas específicas, no entanto, fornecem uma estrutura geral do espaço (Gil Filho, 2012b).

Assim, "todas as espacialidades são parte de um sistema simbólico que estrutura funcionalmente a experiência humana. $\bigcirc$ espaço se apresenta como um a priori nas relações estabelecidas entre a consciência e a experiência; assim como é um fundamento necessário aos diversos sistemas simbólicos" (Gil Filho, 2012b, p. 63). As relações sociais estabelecidas no espaço junto aos devotos constituem o lugar sagrado no qual, segundo Rosendahl (1995), contém em si um sentido de obrigação intrínseca encorajando e exigindo devoção, reforçando o compromisso emocional do devoto.

O compromisso com a religião e a devoção do indivíduo religioso está baseado na ideia da existência de espaços sagrados onde não há imperfeição e guia o ser humano para suportar as infelicidades da vida, conduzindo-o a imaginar realidades mais profundas do que as que seus sentidos revelam (Rosendahl, 1995), sendo possível compreender que "o homem consagra o espaço porque sente necessidade de viver num mundo sagrado, de mover-se em um espaço sagrado. $\bigcirc$ homem religioso, desta maneira, se exprime sob formas simbólicas que se relacionam no espaço" (Rosendahl, 1995, p. 64). A ideia apresentada pela referida autora reflete na consolidação das religiões de matriz africana no Brasil durante o período colonial:

3 CASSIRER, E. A filosofia das formas simbólicas - terceira parte: fenomenologia do conhecimento. Trad. E. A. de Souza. São Paulo: Martins Fontes, 2011 
Os terreiros que, como vimos, estavam presentes nas cidades brasileiras desde o período colonial, tornaram-se também núcleos privilegiados de encontro, lazer e solidariedade para negros, mulatos e pobres em geral que encontraram neles o espaço onde reconstruir suas heranças e experiências sociais, afirmando sua identidade cultural. E a religião, restituindo algum conforto espiritual e esperança para grupos tão perseguidos e estigmatizados, pôde desempenhar seu papel clássico que é o de tornar o sofrimento suportável e fazer da fé uma forma de prosseguir mesmo diante da dissolução do mundo ao redor (Silva, 2005, p. 56).

As formas simbólicas expressam junto ao espaço o compromisso e a devoção do ser humano ao sagrado. A ritualização do espaço permite conectar o sagrado ao profano a partir de práticas litúrgicas, no qual no Candomblé destacam-se as cerimônias conduzidas pelas canções que remetem uma memória ancestral conduzida oralmente em ioruba arcaico, cujo "os praticantes conhecem o sentido dos cantos e dos louvores, mas não necessariamente o conteúdo de cada palavra. Como costuma ser dito: 'esta é a língua falada pelos orixás"' (Barros, 2000, p. 36). Nesse sentido, o lugar cantado se torna o espaço da experiência do sagrado e do vínculo afetivo em meio aos símbolos que o estruturam como cosmicizado.

lugar comporta objetos e valores através dos símbolos, signos e significados. É no lugar que as relações sociais ocorrem, e através delas os valores são compartilhados. A topofilia está ligada a estes valores quando surge no indivíduo a sensação de pertencimento ao lugar. Com o compartilhamento dos valores e das memórias, temos então a possibilidade das análises acerca da identidade de cada indivíduo e do grupo (Torres; Kozel, 2010, p. 130).

Com isso, pode-se considerar que, nos rituais, cultos ou festas públicas de Candomblé, a música é o elemento que permite a comunicação entre o centro ${ }^{4}$ e o cosmo. Por meio da música e da dança, é possível contemplar a forma de representação do orixá; ilustrando-se palavras e lendas, torne-se possível ouvir os mitos das divindades africanas pela música e, "através das letras, a música se torna o meio que transporta o conteúdo histórico-literário da tradição oral" (Lühning, 1990, p. 117).

\section{A música como elo comunicacional entre Orum e Ayê}

Para Blacking (2007), a música é o sistema simbólico primário do pensamento humano e uma parte da construção social da vida humana, uma vez que o fazer musical é um tipo especial de ação social, capaz de influenciar outros tipos de ação social; portanto, "a música não é apenas reflexiva, mas também gerativa, tanto como sistema cultural quanto como capacidade humana" (Blacking, 2007, p. 201). Para o autor, a música pode ser entendida como um quadro inato

4 espaço sagrado reproduz a criação do mundo num microcosmo que procura representar a cosmogonia, a criação do universo a partir de um embrião, um "centro". Logo, segundo o autor, "todo lugar que manifesta a inserção do sagrado no espaço profano também era considerado um centro” (Eliade, 1991, p. 53). 
característico de capacidades cognitivas e sensoriais no qual os seres humanos estão sujeitos a utilizar na comunicação e na produção de sentido do lugar identificado segundo a paisagem que o reflete a partir dos elementos sonoros.

As paisagens sonoras concedem identidades aos lugares, e agem direta e constantemente em seus moradores na contribuição à perpetuação das falas e sotaques, dos gostos musicais, e na evocação de paisagens do passado, o que reforça valores existentes em cada indivíduo, que pode contribuir para sua fixação em lugares distintos, e à criação do sentimento de pertencimento a eles, pelo fato de apresentarem sonoridades que concedem familiaridade na paisagem (Torres; Kozel, 2010, p. 125).

Assim, quando se fala no sentido da música nos terreiros, não se trata apenas de um elemento simbólico que faz parte das liturgias da casa, mas de um princípio que carrega e reforça uma cultura reconstruída a partir da união de elementos étnicos com um princípio em comum: resistir ao sistema escravista brasileiro e buscar fixar suas raízes culturais (Tinhorão, 2008). De acordo com Barros (2000), o mundo dos sons e dos textos falados, gestos, expressões corporais, dissemina um conjunto de significados ordenado pela sua inserção dos distintos ritos nas comunidades-terreiro, sendo possível identificar um lugar a partir da paisagem descrita por meio dos sons, uma vez que "a paisagem sonora é cultural, pois reflete a identidade de um lugar e de seus habitantes. Os sons do trânsito possuem, além dos sons dos motores, códigos que são específicos em cada grupo social" (Torres; Kozel, 2010, p. 127).

Lühning (1990) aponta que a música e as danças que acompanham as entidades expressam o caráter do orixá: acontecimentos míticos e históricos que revelam suas conquistas, defeitos, falhas e dificuldades servem como exemplo aos seres humanos, e, por meio das letras, a música se torna o elemento intermediário que transporta o conteúdo histórico-literário da tradição oral; como afirma Kong (2009), os textos musicais devem ser entendidos como diálogos culturais construídos a partir de um contexto social e histórico particular que se refletem no sentido do lugar.

Como toda música religiosa em seu contexto original, a música de Candomblé é funcional. Em toda cerimônia, pública ou privada, a música desempenha um papel primordial, já que o culto não seria possível sem ela. As funções musicais são várias, sendo a mais generalizada a de chamar os orixás e favorecer sua presença entre os presentes. Essa função se assinala em cerimônias sociais, funerais, de purificação, iniciação ou comunhão. $\bigcirc$ menor ato litúrgico é acompanhado de cantigas rituais ou música de percussão, constituindo, portanto, um repertório muito extenso (Béhague, 1976, p. 131). 
Para Barros (2000), o discurso litúrgico das cantigas do candomblé revela uma visão de mundo que se apresenta nas letras das canções e no ritmo executado pelos ogãs alabês, ${ }^{5}$ responsáveis pelos toques rituais e pela "alimentação" e conservação dos tambores chamados atabaques. Os tambores têm diferentes nomes, que variam de acordo com sua capacidade sonora: o maior é o rum, o do meio rumpi e o menor lê. Segundo Cardoso (2006), os atabaques não são apenas tambores que reproduzem um tipo de som quando tocados, o valor simbólico atribuído é de uma divindade, motivo pela qual são "vestidos" e "alimentados", assim descrito por Pierre Verger (1981, p. 33):

No início da festa, três atabaques de tamanhos diferentes, denominados run, rumpi e lê, acompanhados por um sino de percussão, o agogô, tocam apelos ritmados às diversas divindades. Esses atabaques apresentam uma forma cônica e são feitos com uma única pele, fixada e esticada por um sistema de cravelhos para os nagôs e os gegês, e por cunhas de madeira para os tambores ngomas, de origem congolesa e angolana. Tais instrumentos foram batizados e, de vez em quando, é preciso manter sua força (o axé), por meio de oferendas e sacrifícios. Os atabaques desempenham um duplo papel, essencial nas cerimônias: o de chamar os orixás no início do ritual, e quando os transes de possessão se realizarem, o de transmitir as mensagens dos deuses. Somente o "alabê" e seus auxiliares, que tiveram uma iniciação, tem o direito de tocá-los. Nos dias de festa, os atabaques são envolvidos por largas tiras de pano, nas cores do orixá invocado. Durante as cerimônias, eles saúdam, com um ritmo especial, a chegada dos membros mais importantes da seita e estes vêm curvar-se e tocar respeitosamente o chão, em frente da orquestra, antes mesmo de saldar o pai ou mãe-de-santo do terreiro. No caso de um desses atabaques ser derrubado ou cair no chão durante uma cerimônia, esta é interrompida por alguns instantes, em sinal de contrição.

A personificação dos atabaques como divindades, representa a criação de símbolos que são exportados à materialidade como afirmam Pereira e Gil Filho (2012) proporcionando uma conexão funcional entre o universo dos fatos e o universo simbólico, portanto, "a atividade simbólica modela o mundo em dimensões de experiências que realiza o ser" (Pereira; Gil Filho, 2012, p. 43). Considerando que ambos os autores concebem o espaço sagrado entre categorias de expressão e representação, os instrumentos musicais do candomblé, nesse sentido, têm muito mais que um papel musical, eles passam a representar o sagrado materializado no espaço, como é, por exemplo, o agogô, ligado a Oxalá, a divindade conhecida como "o pai de todos", sendo utilizado na festa de outros santos e estando ligado ao fenômeno da possessão (Cardoso, 2006).

Para além da concepção dos tambores como divindades no terreiro, é possível pensá-lo da perspectiva de "geossímbolos", definidos como "um lugar, um itinerário, uma extensão que, por razões religiosas, políticas ou culturais, aos olhos de certas pessoas e grupos étnicos assume

$5 \bigcirc$ título alabê pode ser subdividido em outras duas categorias. Otun-alabê, o da direita, mais velho em iniciação e saber, e ossi-alabê, o da esquerda, mais jovem. Essa disposição só pode ser alterada pela morte de um de seus integrantes (Barros, 2000, p. 40). 
uma dimensão simbólica que os fortalece em sua identidade" (Bonnemaison, 2002, p. 109). Dessa forma, os atabaques assumem uma importância dentro da comunidade do terreiro, tendo um papel mediador entre os dois espaços, Orum e Ayê, além de sua funcionalidade como um instrumentos de percussão. Simbolicamente, transformam-se nos porta-vozes dos Orixás. Sendo assim, apresentam-se como elementos estruturantes da paisagem do terreiro, carregando elementos como sentimentos e valores como a ancestralidade, que constroem e caracterizam o espaço.

Lühning (1990) aponta a música como um fator que está intimamente ligado ao fenômeno da possessão do orixá, sendo uma manifestação direta do sagrado descrita por Eliade (1991) como uma hierofania. O complexo de crenças iorubá tem um conceito que divide o mundo em dois planos: "o aiê é a própria realidade concreta, física, incluindo ainda toda a humanidade e os seres naturais. O orum é uma realidade paralela ao aiê, um espaço sobrenatural que não se coloca no mesmo plano deste e é povoado por habitantes que têm seu equivalente no aiê" (Fonseca, 2006, p. 104).

Ambos os planos são interligados por uma força vital responsável pelo equilibrio do universo, o axé, tornando possível o processo de criação da vida, "é uma força que pode ser transmitida, conduzida e acumulada e perdida, podendo estar presente em substratos materiais e simbólicos" (Fonseca, 2006, p. 104). Tratando-se de uma força fundamental, o axé pode enfraquecer ou até mesmo sumir, desta forma os seres humanos são incumbidos de renovar e manter a força do axé podendo ser encontrado segundo Fonseca (2006), nas substâncias que dão vida aos seres de todos os reinos naturais: mineral, vegetal e animal. Para o autor, há uma relação de troca de energias entre ambos os espaços na qual a música tem um papel fundamental, visto que "nesse contrato, necessário e não negligenciável, coloca-se uma verdade inscrita na narrativa mítica, sobre a qual se baseia toda a visão de mundo" (Fonseca, 2006, p. 105).

A execução musical nos cultos de Candomblé é peça-chave de constituição simbólica da cena ritual, podendo-se considerar que as cerimônias estabelecem comportamentos, mas também maneiras de significação com o propósito de desempenhar etapas que estão intimamente ligadas ao sistema de crenças buscando constituir um laço íntimo entre o ser humano e os deuses, visto que, como afirma Geertz (2008), ajusta as ações humanas a uma ordem cósmica concebida e idealiza imagens da ordem cósmica no plano da realidade humana. Nesse sentido, os símbolos sagrados sintetizam o ethos de uma sociedade e sua visão de mundo, portanto "o ethos de um grupo torna-se intelectualmente razoável porque demonstra representar um tipo de vida idealmente adaptado ao estado de coisas atual que a visão de mundo descreve" (Geertz, 2008, p. 67).

A conexão dos planos Orum e Ayê revela uma ligação entre dois lugares por meio da memória a partir do fazer musical que carrega nas letras das suas canções elementos simbólicos que transmitem imagens que revelam o caráter e a identidade do lugar, sendo possível compreender que "a construção e o fortalecimento de identidades são possíveis por meio dos textos musicais (o ritmo, as letras e os diferentes estilos)" (Kong, 2009, p. 156). Da mesma forma, Fonseca (2006) descreve a música como um dos elementos simbólicos que estabelece uma 
relação de reciprocidade entre os planos espirituais presente no Candomblé, tratando-se, em certos momentos, do principal de todos os elementos.

Sua participação como elemento operacional inscreve-se não só numa visão de mundo particular, mas torna-se, muitas vezes, a própria razão de ser dessa visão. Como quer Merriam6 (apud Nettl, 1983, ${ }^{7}$ p. 131), não se trata, então, só de "música na cultura", mas também de "música como cultura", pois sem ela o contrato com os deuses está inviabilizado e, portanto, também, todo o ethos da comunidade (Fonseca, 2006, p. 108).

A música, mas também as letras e danças correspondem a uma forma de expressão cultural que manifesta a identidade cultural do lugar - nesse caso, o terreiro - e das relações sociais que se estabelecem no espaço desenvolvendo práticas e comportamentos que preservam e dão suporte ao território religioso. Pinto (2001) considera a música um processo de significado social capaz de gerar sistemas que ultrapassam seus aspectos sonoros e que complementam um conjunto de elementos como a performance, a corporalidade - que inclui a dança - e as estruturas musicais como simbolismo que delimita o território e o classifica como espaço religioso. Para Kong (2009), a música tem elementos culturais, simbólicos, étnicos e geográficos que são reestruturados por meio da memória criando um elo entre espaço e tempo em que a música caracteriza o espaço, pois transmite por meio das letras a identidade cultural do lugar.

Aqui música não é entendida apenas a partir de seus elementos estéticos, mas, em primeiro lugar, como uma forma de comunicação que possui, semelhante a qualquer tipo de linguagem, seus próprios códigos. Música é manifestação de crenças, de identidades, é universal quanto à sua existência e importância em qualquer que seja a sociedade. Ao mesmo tempo é singular e de difícil tradução, quando apresentada fora de seu contexto ou de seu meio cultural (Pinto, 2001, p. 223).

Nesse sentido, a música atua como elemento sacralizador do espaço do terreiro, pois se faz presente em todas as celebrações dentro da casa, desde a iniciação de um novo membro, até no cotidiano dos integrantes da comunidade. É a partir das canções que o indivíduo se conecta com o orixá por meio do fenômeno da possessão criando uma íntima ligação entre sagrado e profano, visto que "o som, assim como a palavra, é importante, pois conduz e proporciona o axé. Acompanhado ou não de instrumentos musicais, possui uma força especial que é zelosamente guardada na memória" (Barros, 2000, p. 39). Assim, a música nos ritos de Candomblé torna-se um elemento indispensável para sacralizar o espaço e renovar o axé a partir dos sacrifícios e da preservação do elo entre o ser humano orixá "dono da sua cabeça", mantendo viva a memória africana, e a cosmogonia do lugar.

Segundo Corrêa (2012), a religião constrói um território que constitui uma dimensão espacial da cultura, ou seja, é uma forma de expressão cultural no espaço que abrange

6 MERRIAN, A. The Anthropology of Music. Evanston, MI: Northwestern University Press, 1964.

7 NETTL, B. The Study of Ethnomusicology: Twenty-nine Issues and Concepts. Urbana, IL: University of Illinois Press, 1983. 
determinados conjuntos de práticas e significados. Para Silva (2005), o Candomblé reproduz a cultura dos negros africanos trazidos para o trabalho escravo no Brasil por meio dos rituais sagrados como forma de resistir ao sistema escravista, uma vez que, com suas familias dispersas, a união entre distintas etnias sincretiza divindades de diferentes lugares até se formar o que se entende hoje por Candomblé brasileiro. É assim que os terreiros se tornam espaços de reflexo da cosmogonia africana, procurando, por meio de rituais e cultos, retomar a herança cultural dos ancestrais africanos.

Instalar-se num território equivale, em última instância, a consagrá-lo: Quando a instalação já não é provisória, como nos nômades, mas permanente, como é o caso dos sedentários, implica uma decisão vital que compromete a existência de toda a comunidade. "Situar-se" num lugar, organizá-lo, habitá-lo - são ações que pressupõem uma escolha existencial: a escolha do Universo que se está pronto a assumir ao "criá-lo". Ora, esse "Universo" é sempre a réplica do Universo exemplar criado e habitado pelos deuses: participa, portanto, da santidade da obra dos deuses (Eliade, 1991, p. 46).

De modo geral, para Fonseca (2006), é possível dizer que os rituais de candomblé são práticas estabelecidas de forma cerimonial que objetivam cumprir dadas etapas ligadas ao sistema de crenças que operam no modo de afirmar forças "emotivas que interligam deuses e homens, integrando o indivíduo à comunidade-de-santo" (Fonseca, 2006, p. 106). Para o autor, é possível compreender que as principais cerimônias são realizadas com a presença da música, o elemento indispensável no qual estabelece uma relação entre o orixá e seu filho.

No mundo dos candomblés, se o desigual contrato de trocas entre a enorme força dos deuses e a singela dádiva dos homens se dá por meio de um conjunto de símbolos, é pelo fazer musical que, por excelência, isso acontece. Todos os principais procedimentos litúrgicos só se podem realizar tendo a música, em suas diversas modalidades, como veículo entre o mundo ordinário, a terra ou aiê, e o extraordinário, o céu ou orum (Fonseca, 2006, p. 113).

Gil Filho (1999, p. 114) apresenta o espaço de representações como um espaço vivo com ligações afetivas, constituindo-se um "lócus da ação e das situações vivenciadas. É relacional em percepção, diferencialmente qualitativo e dinâmico e de natureza simbólica”. Para o autor, há uma autonomia dada ao fato religioso de modo que suas práticas acabam por constituir um ethos social, o qual age junto ao poder estabelecendo uma ação institucional abrangendo espacialmente comportamentos e significados que delimitam as ações de um grupo ou instituição religiosa que se apropriam simbolicamente do espaço delimitado tornando-o território. Os rituais de Candomblé fazem parte das práticas dos grupos que constituem o terreiro, em que as principais ações que ocorrem são mediadas pelo fazer musical no qual constroem e sacralizam o espaço a partir dos símbolos e da manifestação direta do sagrado, podendo ser evidenciadas a partir da chegada dos orixás no corpo do seu filho. 
A religião imprime uma lógica no espaço marcado por momentos de transcendência que se diferenciam a cada tempo sagrado concebendo lugares, territórios e itinerários sagrados (Rosendahl, 2012). A análise do espaço, da religião e da cultura propõe uma discussão abrangente dentro da Geografia, em que é possível explicar que o espaço é configurado pelas ações dos grupos religiosos, sendo uma das muitas manifestações culturais que imprimem na paisagem símbolos imbuídos de significados e utilidades dentro do próprio espaço que revelam e constituem traços fundamentais do ser humano (Corrêa, 2012, p. 135), criados por diversos grupos sociais, demarcando-o para determinados fins.

A prática musical nos terreiros de Candomblé pode ser vista como um elemento simbólico propulsor das ações sociais presente no espaço. De acordo com Rosendahl (2012), existe um impulso que leva o homem religioso a agir sobre seu ambiente e qualifica-o com formas espaciais diretamente ligadas às suas necessidades. "São marcas simbólicas que respondem aos desejos do devoto em suas práticas espaciais" (Rosendahl, 2012, p. 25). As práticas espaciais religiosas contribuem para a criação de um território que possibilita o fortalecimento das experiências religiosas coletivas e individuais garantindo e estabelecendo o domínio dos grupos religiosos no espaço.

O espaço se torna palco de ações que o dotam de significados onde se constrói o sentido de lugar, que Tuan (1980) classifica como o centro de significações construído pela experiência. Portanto, a música proporciona uma comunicação com os sentidos que constroem a identidade do lugar a partir das canções e letras (Kong, 2009), ou seja, "a música é capaz de transmitir 'imagens' de um lugar, podendo servir como fonte primária para entender o caráter e a identidade dos lugares" (Castro, 2009, p. 13). Há um campo de conexões simbólicas no Candomblé entre o fazer musical e o ritual:

[...] que extrapolam o corpus tanto do ritual, como encadeamento de procedimentos litúrgicos, como da música enquanto fenômeno articulado segundo leis próprias [...]. O contrato estabelecido entre deuses e homens realizado por meio dos toques dos tambores correlaciona-se a conjuntos simbólicos com múltiplas vocações. Assim, sem a tentativa de compreensão de uma visão de mundo como força subjacente à prática ritualística descrita nos mitos, essa correlação seria inócua, tornando-se uma mera descrição formal de aspectos dos ritos ou da prática musical. No mundo dos candomblés, se o desigual contrato de trocas entre a enorme força dos deuses e a singela dádiva dos homens se dá por meio de um conjunto de símbolos, é pelo fazer musical que, por excelência, isso acontece (Fonseca, 2006, p. 113).

Para Cassirer (1977), a linguagem como forma simbólica junto à arte, à religião e ao mito faz parte da construção da paisagem sonora, visto que é a partir do processo da fala que se constituem os signos que consolidam as relações coletivas dos grupos sociais, tornando possível o processo de comunicação: "a própria música se tornou imagem das coisas" (Cassirer (1977, p. 221) e se manifesta na paisagem sonora. A linguagem nos terreiros é um elemento fundamental para o aprendizado, no qual a palavra, como descreve Barros (2000), tem uma condição especial, com poder para animar a vida e movimentar o axé contido na natureza. Pedidos, súplicas, todos devem ser verbalizados, sendo inconcebível rezar aos orixás em silêncio, portanto, o 
aprendizado das liturgias da casa é por meio da oralidade, sendo repassado dos mais velhos aos mais novos por meio da memória dos elementos sagrados.

Portanto, a música é muito relevante nos cultos de matriz africana, especificamente no Candomblé, religião que se discute aqui. A escolha do fator musical junto à Geografia e às Ciências da Religião visa contribuir com as pesquisas acerca de cultura e religião, ainda que este exercício teórico se apresente timidamente no meio acadêmico. Baseando-se nos estudos de Rosendahl e principalmente de Lily Kong, foi possível iniciar a elaboração de uma relação entre música e espaço, visto que cada execução musical no espaço reflete modelos de comportamentos fundamentais buscando dar continuidade a uma cultura.

A música também pode ser um elemento favorável à construção do espaço sagrado como lócus material no que se refere à incorporação dos orixás nos filhos de santo, uma vez que as cantigas buscam introduzir a presença do sagrado nas cerimônias religiosas, e, por meio do simbólico, os instrumentos musicais, cujo significado é muito maior do que apenas o de reprodutores de som. Segundo Cardoso (2006), os instrumentos representam o poder da divindade e estão intimamente ligados ao fenômeno da possessão, pois, quando são tocados, têm o axé específico que contribui para a incorporação do orixá no seu filho. Nesse sentido, a música é a manifestação de crenças, de identidades, sendo um elemento universal cuja existência é de suma importância para qualquer sociedade, ao mesmo tempo em que é individual e de difícil compreensão quando apresentada fora de seu contexto ou meio cultural (Pinto, 2001).

Cassirer (1977) afirma que vivemos num mundo simbólico onde a religião faz parte de um conjunto de formas simbólicas que estruturam a realidade humana, é definido e destacado pela linguagem, em que se opera toda a energia do sistema simbólico. Os mitos culturais são as formas permanentes nas quais o homem vive e existe, de modo que a concepção de mundo físico está relacionada ao mundo moral e, portanto, "as cosmogonias das religiões tradicionais se relacionam com suas doutrinas morais" (Gil Filho, 2012b, p. 52). O homem se cercou de formas linguísticas, imagens artísticas, símbolos míticos e, conforme Moura (2000), não consegue mais ver algo sem a intervenção do meio artificial, do símbolo, uma vez que se tornou um animal symbolicum, que vive num universo puramente simbólico, como descrito por Cassirer (1977).

A comunicação com o sagrado, a fé, é realizada por meio da linguagem, resultando na experiência do homem religioso retratada a partir da distinção social e espacial que resulta em uma nova ordem na sua vida, que passa a ser transposta pela lei sagrada. Assim, o fiel convertido pelo discurso religioso assume novas práticas sociais no espaço:

O espaço material funciona, dessa maneira, como propulsor e extensão do fenômeno religioso Propulsor no sentido de ser o meio das percepções. Extensão, pois nas paisagens religiosas se apresenta como símbolo espacializado (Fernandes; Gil Filho, 2011, p. 224).

Ao descrever o homem como animal simbólico (animal symbolicum), Cassirer acentua a importância da atividade simbólica como elemento estruturante da realidade humana, uma vez que a religião pode ser compreendida como uma manifestação cultural que dá significado ao mundo sensível. Geertz (2008) esclarece que o homem é um animal atado a teias de significados 
que ele mesmo teceu, visto que os símbolos pertencem ao mundo dos significados, logo, todas as relações simbólicas são significativas.

Os significados só podem ser "armazenados" através de símbolos: uma cruz, um crescente ou uma serpente de plumas. Tais símbolos religiosos, dramatizados em rituais e relatados em mitos, parecem resumir, de alguma maneira, pelo menos para aqueles que vibram com eles, tudo que se conhece sobre a forma como é o mundo, a qualidade de vida emocional que ele suporta, e a maneira como deve comportar-se quem está nele (Geertz, 2008, p. 92).

Para Asad (2010), os símbolos religiosos segundo Geertz produzem dois tipos de atitude, disposição e motivação: as motivações tornam-se significativas no que tange os fins a qual elas foram concebidas e conduzidas, enquanto as disposições são tornadas significativas no que se refere às condições as quais se concebe que elas surjam. É certo afirmar que a religião estabelece cronogramas de práticas fundamentais que estabelecem ao ser humano uma ordem de viver a sua própria realidade, uma vez que "todo ser humano tem profunda necessidade de uma ordem geral de existência que os símbolos religiosos funcionam para satisfazer essa necessidade" (Asad, 2010, p. 272).

A essência da ação religiosa é composta, de certa forma, por um determinado complexo de símbolos que têm uma autoridade persuasiva. A religião induz e constrói motivações e disposições, cria ideias gerais de ordem, do contrário, seria apenas um conjunto de normas morais. Portanto, "os conceitos religiosos servem aos fiéis um arcabouço de ideias gerais, não apenas a questões metafísicas, mas a grande parte da existência humana" (Araújo, 2015, p. 102).

Geertz (2008) propõe então que reconstituir o papel social e psicológico da religião não é apenas buscar paralelismos entre rituais e laços seculares específicos. Trata-se de "compreender de que maneira as noções dos homens, embora implícitas, do 'verdadeiramente real' e as disposições que essas noções induzem neles, dão um colorido a seu sentido do racional, do prático, do humano e do moral" (Geertz, 2008, p. 90).

Portanto a religião assume um papel sistemático no que tange a construção social de princípios de organização da realidade humana como forma de enfrentar o caos, os desarranjos que o indivíduo se depara nas circunstâncias da sua existência buscando alcançar uma homogeneidade a partir das relações socioestruturais de um grupo como forma de conhecimento do mundo.

\section{Considerações finais}

A religião como expressão cultural e simbólica é fundamental para compreender as relações na sociedade, sejam individuais ou sociais, uma vez que a religião apresenta princípios que buscam esclarecer o sentido da existência humana. Assim, é imprescindível haver um debate entre a Geografia e as Ciências da Religião, uma vez que os temas estão intimamente conectados no que tange às expressões simbólicas que a religião imprime no espaço. $\bigcirc$ tema proposto visa estimular estudos e discussões acerca do Candomblé e de suas dimensões espaciais pautadas no fazer musical, considerando a música como expressão simbólica que dinamiza e territorializa as ações dos praticantes do candomblé. 
Ao oferecer uma perspectiva de estudos entre geografia, música e religião, pretendemos discutir um viés de análise a partir de um elemento que permite estabelecer uma conexão entre diferentes espaços que permeiam a existência humana. A música no Candomblé é um elemento que mobiliza um vínculo espiritual entre humanos e divindades que habitam outro plano espacial e que retornam ao plano terreno para que a força que equilibra o universo possa ser restabelecida naquele espaço, permitindo compreender o fazer musical como uma condição de consagração do espaço, uma vez que em todas as obrigações de uma casa a presença da música é indispensável para a aproximação dos orixás.

Certamente, esse debruçar epistemológico sobre a análise do espaço religioso do Candomblé a partir da música abre novas perspectivas de análise da categoria espaço sagrado, sobretudo no que diz respeito a sua construção, seja pelas formas simbólicas ou hierofânicas. Aparentemente, a música se enquadra em ambas as estruturas de pensamento, da Geografia da Religião, sendo uma expressão simbólica que permite a manifestação do sagrado no espaço. Sendo assim, cabe a possibilidade de estender o debate sobre a música e a produção espacial para além da temática proposta neste texto, como uma ferramenta de pesquisa e produção do conhecimento do fenômeno religioso e da dinâmica espacial humana.

\section{Referências}

ARAÚJO, C. S. Religião, sagrado e poder: considerações conceituais em Geertz, Terrin e Deleuze. Ciberteologia - Revista de Teologia \& Cultura, São Paulo, v. 11, n. 51, p. 99-111, 2015.

ASAD, T. A construção da religião como uma categoria antropológica. Cadernos de Campo, São Paulo, v. 19, n. 19, p. 263-284, 2010.

BARROS, J. F. Mito, memória e história: a música sacra. Espaço e Cultura, Rio de Janeiro: Uerj, n. 9-10, p. 35-48, 2000.

BÉHAGUE, G. Correntes regionais e nacionais na música do Candomblé baiano. Afro-Ásia, Salvador: Centro de Estudos Afro-Orientais da Universidade Federal da Bahia, n. 12, p. 129-140, 1976. doi: http://dx.doi.org/10.9771/aa.v0i12.20778.

BLACKING, J. Música, cultura e experiência. Cadernos de Campo, São Paulo, v. 16, n. 16, p. 201-218, 2007.

BONNEMAISON, J. Viagem em torno do território. CORREAA, R. L.; ROSENDAHL, Z. (Org.). Geografia cultural: um século. Rio de Janeiro: Ed. Uerj, 2002. v. 3. p. 83-131.

CARDOSO, A. N. N. A linguagem dos tambores. Tese (Doutorado em Etnomusicologia) Escola de Música, Universidade Federal da Bahia, Salvador, 2006.

CASSIRER, E. Ensaio sobre o homem: introdução a uma filosofia da cultura humana. Trad. Vicente Feliz de Queiroz. São Paulo: Mestre Jou, 1977.

CASTRO, D. Geografia e música: a dupla face de uma relação. Espaço e Cultura, Rio de Janeiro: Uerj, n. 26, p. 7-18, 2009. 
CORRÊA, R. L. Espaço e simbolismo. In: CASTRO, I. E.; GOMES, P. C. C.; CORRÊA, R. L.

(Org.). Olhares geográficos: modos de ver e viver o espaço. Rio de Janeiro: Bertrand Brasil, 2012. p. 133-153.

ELIADE, M. Imagens e símbolos: ensaio sobre o simbolismo mágico-religioso. Trad. Sonia Cristina Tamer. São Paulo: Martins Fontes, 1991.

FERNANDES, D.; GIL FILHO, S. F. Geografia em Cassirer: perspectivas para a geografia da religião. GeoTextos, v. 7, n. 2, p. 211-228, 2011.

FONSECA, E. J. M. “... Dar rum ao Orixá...” : ritmo e rito nos Candomblés Ketu-Nagô. Textos

Escolhidos de Cultura e Arte Populares, Rio de Janeiro, v. 3, n. 1, p. 101-16, 2006.

GEERTZ, C. A interpretação das culturas. Rio de Janeiro: LTC, 2008.

GIL FILHO, S. F. Espacialidades de conformação simbólica em Geografia da Religião: um ensaio epistemológico. Espaço e Cultura, Rio de Janeiro: Uerj, n. 32, p. 78-90, 2012a.

GIL FILHO, S. F. Geografia das formas simbólicas em Ernst Cassirer. Visões do Brasil: estudos culturais em geografia. Salvador: Ed. Ufba, 2012b. p. 47-66.

GIL FILHO, S. F. Espaço de representação e territorialidade do sagrado: notas para uma teoria do fato religioso. Ra'ega - O Espaço Geográfico em Análise, v. 3, p. 91-129, 1999.

KONG, L. Música popular nas análises geográficas. In: CORRÊA, R. L.; ROSENDAHL, Z. (Org.). Cinema, espaço e música. Rio de Janeiro: Ed. UERJ, 2009. p. 129-175.

LÜHNING, A. Música: coração do candomblé. Revista da USP, São Paulo, n. 7, p. 115-124, 1990.

MARINHO, S. C. Um homem, um lugar: geografia da vida e perspectiva ontológica. Tese (Doutorado em Geografia) - Faculdade de Filosofia, Letras e Ciências Humanas, Universidade de São Paulo, São Paulo, 2010.

MOURA, M. R. O simbólico em Cassirer. Ideação, Feira de Santana, n. 5, p. 75-85, 2000.

PEREIRA, C. J.; GIL FILHO, S. F. Geografia da Religião e espaço sagrado: diferenças entre as noções de lócus material e conformação simbólica. Ateliê Geográfico, v. 6, n. 1, p. 35-50, 2012.

PINTO, T. O. Som e música: questões de uma antropologia sonora. Revista de Antropologia, v. 44, n. 1, p. 222-286, 2001.

ROSENDAHL, Z. O sagrado e sua dimensão espacial. In: CASTRO, I. E.; GOMES, P. C.; CORREAA, R. L. (Org.). Olhares geográficos: modos de ver e viver o espaço. Rio de Janeiro: Bertrand Brasil, 2012. p. 73-99.

ROSENDAHL, Z. Território e territorialidade: uma perspectiva geográfica para o estudo da religião. Geografia - Temas sobre Cultura e Espaço, Rio de Janeiro: Ed. Uerj, p. 191-226, 2005.

ROSENDAHL, Z. Geografia de religião: uma proposta. Espaço e Cultura, Rio de Janeiro: Uerj, n. 1, p. 45-74, 1995. 
SILVA, V. G. Candomblé e umbanda: caminhos da devoção brasileira. 5a ed. São Paulo: Selo Negro, 2005.

TINHORÃO, J. R. Os sons dos negros no Brasil: cantos, danças, folguedos: origens. São Paulo: Editora 34, 2008.

TORRES, M. A.; KOZEL, S. Paisagens sonoras: possíveis caminhos aos estudos culturais em geografia. Ra'ega - O Espaço Geográfico em Análise, v. 20, p. 123-132, 2010.

TUAN, Y.-F. Topofilia: um estudo da percepção, atitudes e valores do meio ambiente. São Paulo: Difusão, 1980.

VERGER, P. Orixás: deuses iorubás na África e no Novo Mundo. Salvador: Corrupio, 1981. 